\title{
Psicologia analítica e a interpretação dos personagens dos sonhos lúcidos
}

\author{
José Felipe Rodriguez de Sá,`Ermelinda Ganem Fernandes \\ Instituto Junguiano da Bahia, Candeal Salvador, BH - Brasil
}

Resumo

\begin{abstract}
Os sonhos lúcidos são descritos como a consciência de estar sonhando durante o sonho e a capacidade de alterá-lo narrativamente. Uma breve introdução sobre tema será desdobrada, seguida pela análise de uma das características marcantes desse fenômeno: os personagens que habitam esse estado onírico, possuidores de um grau de autonomia e facilidade de comunicação surpreendente se comparados aos sonhos comuns. Na intenção de averiguar substrato psíquico dessas entidades autônomas será conduzida uma investigação sob a ótica da psicologia analítica, privilegiando o conceito Junguiano de "sombra" e a teoria dos complexos. Por fim, será destacada a importância dessa análise para o processo de individuação.
\end{abstract}

Palavras-chave: inconsciente; individuação; sonhos; sono REM; teoria junguiana.

\section{Analytical psychology and the interpretation of lucid dream characters}

\begin{abstract}
Experts describe lucid dreams as the awareness of being in a state of dreaming during the dream itself and the ability to change its narrative. A brief introduction to this theme will be detailed, followed by an analysis of the striking features of this phenomenon: the presence of the characters that inhabit the dream state, which have a surprising degree of autonomy and ease of communication when compared to ordinary dreams. Intending to investigate the psychic substrate of autonomous entities, an investigation will be performed from the perspective of analytical psychology, emphasizing the Jungian concept of "shadow" and the theory of complexes. Finally, the importance of this analysis to the process of individuation will be highlighted.
\end{abstract}

Keywords: dreams; individuation; Junguian Theory; sleep REM; unconscious.

\section{Introdução}

O sonho lúcido é um estado psicofisiológico do sono onde um sujeito percebe que está sonhando e pode mudar o enredo do sonho de acordo com sua vontade. Durante essa experiência a consciência é razoavelmente preservada e o sujeito relata ter sensações excepcionalmente realistas (HOLZINGER; LABERGE; LEVITAN, 2006). Outras experiências associadas a este fenômeno relativamente raro são os falsos despertares e as chamadas "experiências fora do corpo" (LABERGE, 1980, 1990).

O objetivo do presente trabalho, além de introduzir as principais características da lucidez onírica, é dar uma leitura psicodinâmica aos personagens que surgem nos sonhos lúcidos. Nesse sentido, é enquadrá-los dentro da visão Junguiana dos sonhos, com o suporte de três conceitos caros à psicologia analítica: a teoria dos complexos, a função compensatória dos sonhos e o processo de individuação. Após a introdução desses conceitos, serão discutidos os benefícios de dialogar com esses fragmentos cindidos da psique - no intuito de reabsorvê-los - e como esse trabalho psicológico contribui para o processo da individuação.

\section{Características gerais da lucidez onírica}

Os sonhos lúcidos são um fenômeno psicológico milenar, presente na cultura de diversos povos. Apesar disso só há pouco os sonhos lúcidos foram alvo de investigação científica; sua comprovação empírica é recente, datando do início da década de oitenta (LABERGE, 1990). Desde então há um crescente interesse em torno do assunto, servindo ele de inspiração

\footnotetext{
^Endereço para correspondência: Instituto Junguiano da Bahia. Alameda Bons Ares, 15, Candeal Salvador - Bahia - Brasil.E-mail: zefelipe@yahoo.com, eganem65@gmail.con
}

até no campo artístico, aparecendo como tema de filmes (Waking Life, Vanilla Sky) ou servindo como técnica de composição para compositores reconhecidos da música eletrônica atual, vide o exemplo de Richard James vulgo Aphex Twin (GRAD, 1994), considerado o "Mozart" da dance music contemporânea (PRENDERGAST, 2003). Apesar desse crescente interesse popular e científico em torno do tema, há um relativo desconhecimento a respeito dele no universo acadêmico da psicologia brasileira. Uma pesquisa conduzida no banco de dados online da SciELO em busca de artigos de psicologia que abordassem a lucidez onírica apresentou como resultado uma breve menção do tópico em questão num artigo do psiquiatra americano Stanley Krippner (2007) abordando práticas xamanistas, e no artigo "Estado da consciência onírica" da psicóloga Therezinha Moreira Leite (1997). No sistema de busca do Google Acadêmico só foram achados três artigos de um mesmo autor tratando especificamente sobre sonhos lúcidos (MUNIZ, 2001, 2005a, 2005b).

A primeira prova empírica obtida confirmando a existência do sonhar lúcido foi através da tese de doutorado de Stephen LaBerge, um químico formado pela universidade de Stanford que tinha interesse por estados alterados de consciência. LaBerge (1980) divulgou seus achados resumidamente num artigo publicado pelo periódico Perceptual and Motor Skills, no qual relatava a eficácia do Mnemonic Induction of Lucid Dreams (MILD), técnica sobre a qual discorreremos mais tarde.

Logo após a publicação desse estudo outros pesquisadores foram explorando as minúcias deste fenômeno. Greenleaf, Kedzierski e LaBerge (1983) monitoraram as mudanças fisiológicas sexuais durante o sono com base no relato de uma mulher que atingia voluntariamente um orgasmo durante um sonho lúcido, 
o seu corpo tendo uma reação física correspondente à experiência. $\mathrm{O}$ psicólogo alemão Paul Tholey (1983a) publicou um artigo relatando os movimentos voluntários dos olhos durante o sono REM. Descobriu que a direcionalidade desses movimentos coincidia com a história dos sonhos relatada pelos participantes do experimento. Estudos recentes, a exemplo do de Gackenback (2006) falam sobre a correlação entre desenvolvimento cognitivo, videogames e uma frequência maior em sonhos lúcidos. Erlacher e Schredl (2008) demonstraram que tarefas previamente combinadas e executadas durante um sonho lúcido aumentam o batimento cardíaco em comparação a sonhos "normais", não-lúcidos. Há até estudos mais "esotéricos" relacionando sonhos lúcidos com experiências extracorpóreas, um fenômeno onde o sonhador "sai" do seu corpo durante o sono (DEGRACIA et al, 1999).

Outra descoberta importante é o fato de o sonho lúcido ser um fenômeno intrínseco ao sono e estar fortemente correlacionado com o rapid eye movement, fase do sono onde se tem a maioria dos sonhos (BRYLOWSKI; LEVITAN; LABERGE, 1989). Apesar da aparente obviedade desse achado ele tem inegável importância, pois por muito tempo os pesquisadores do campo acreditavam que o sonho lúcido não era de fato um sonho e sim um 'micro-despertar', uma intrusão do estado de vigília no sono (LABERGE, 1990). LaBerge (1993) atribuiu essa resistência a uma confusão devido à visão freudiana do sonho ser uma experiência inconsciente, visão essa ainda influente nesse campo. LaBerge (1993) argumenta que os conteúdos dos sonhos podem ser de fato inconscientes, mas a experiência do sonho não.

Mesmo assentindo que os sonhos lúcidos são relativamente raros, LaBerge (1980) acredita que todos podem aprender a tê-los. Existe uma série de técnicas para se obter os sonhos lúcidos; uma das mais conhecidas é a MILD, criada pelo próprio LaBerge (1990). Ela é dividida em quatro passos:

1) Depois de acordar de um sonho, no início da manhã, repassá-lo várias vezes até memorizá-lo.

2) Quando adormecer novamente, repetir para si próprio: "Na próxima vez em que estiver sonhando quero me lembrar de reconhecer que estou sonhando".

3) Visualizar a volta para o sonho ensaiado, com uma diferença: dessa vez, concentrar-se em perceber que está sonhando.

4) Repetir os itens dois e três até dormir ou sentir que a sua intenção ficou fixada.

LaBerge (1980) documentou a eficácia desta técnica no primeiro artigo científico que dedicou ao assunto. Num experimento que durou três anos, tendo o próprio autor como cobaia, LaBerge (1980) verificou que alguns fatores "psicológicos" eram essenciais para a ocorrência experimental de sonhos lúcidos. Um deles era a motivação da obtenção dos sonhos lúcidos, a qual influi diretamente na frequência da obtenção dos sonhos lúcidos. A outra era a vontade de lembrar dos sonhos. LaBerge (1980) primeiro utilizou a técnica de autossugestão como a sua técnica principal para a indução de sonhos lúcidos. $\mathrm{Na}$ primeira fase do experimento, com duração de um ano e meio, ele conseguiu uma média de 5,4 sonhos lúcidos por mês. Na segunda fase, LaBerge (1980) aplicou a sua técnica MILD, elevando a média para 21,5 sonhos lúcidos por mês, havendo até quatro ocorrências numa única noite. Em termos estatísticos um incremento de $75 \%$ na ocorrência do sonhar lucidamente.

Outro pesquisador importante da área, o gestaltista alemão Paul Tholey (1983b), sugeriu outras técnicas entre as quais as da:

1) Reflexão: o sujeito deve se perguntar, com a frequência que puder, se naquele momento ele está sonhando ou não. Com o passar do tempo as diferenças entre o estado onírico e o de vigília se tornarão ainda mais nítidas, contribuindo assim para facilitar a consciência necessária para alcançar a lucidez durante o sonhar.

2) Intenção: essa técnica envolve o sujeito imaginar uma típica situação de sonho onde ele reconhecerá tal estado.

3) Autossugestão: o sujeito, preferencialmente relaxado no limiar entre sono e a consciência desperta, se autossugere a fim de experimentar um sonho lúcido.

\section{A psicologia dos sonhos lúcidos}

O que a psicologia tem a dizer sobre os sonhos lúcidos? Apesar da pouca menção ao tema nessa área, registros de experiências envolvendo sonhos lúcidos datam da Antiguidade Clássica. Aristóteles de Stágiros (384 - 322 a.C.), um dos fundadores da filosofia Ocidental, comentara num dos seus escritos que muitas vezes, "quando estamos dormindo, há algo na consciência que declara que o que está se apresentando no momento não passa de um sonho" (ARISTÓTELES apud LABERGE, 1990, p. 31). O fenômeno descrito por Aristóteles era lugar-comum nos templos de cura de Aslépio, deus Greco-romano da medicina. Neles se praticavam a chamada "incubação dos sonhos" onde, a partir de uma série de sugestões pré-sono, o paciente era induzido a sonhar com o Aslépio e pedir para o deus curar-lhe a enfermidade durante o sono. Calcula-se que tenham existido na Grécia Antiga cerca de 400 templos de cura (GARFIELD, 1977).

O estudo sistemático e acumulativo desse fenômeno teve de esperar até o século XIX, quando alguns pesquisadores independentes se interessaram pelo o assunto (LABERGE, 1993). Um pioneiro nesses estudos foi o marquês Hervey de Saint-Denys (1823-1892). Esse aristocrata francês passou três décadas se dedicando ao seu objeto de atenção; condensou o conteúdo dos seus 22 volumes de hipóteses e anotações no livro Les Rêves et lês Moyens de lês Diriger (SAINT-DENYS, H., 2007[1867]), publicado em 1867. Dado ao seu zelo, Hervey criticava a ciência do seu tempo por não se dedicar mais ao que veio a ser conhecido mais tarde como "sonhos lúcidos" (HOBSON, 1996; MARTIN, 2004). 
A primeira menção que a psicologia profunda faz ao tema aparece discretamente nas páginas de $A$ Interpretação dos Sonhos, o apoteótico livro do fundador da psicanálise, Sigmund Freud (1856-1939). Freud (1996a, p. 362) comentou situações onde um indivíduo reconhece a irrealidade da situação sonhada, percepção expressa na frase "afinal, isto é apenas um sonho". No entanto Freud (1996a[1900]) estava convencido de que a verbalização do "isto é apenas um sonho" - considerado o "gatilho" básico para se adentrar um sonho lúcido (LABERGE, 1990) tinha intenções defensivas. Permeando essa concepção "defensiva" do "gatilho" lúcido de Freud (1996a[1900], p. 363) há a sua fórmula clássica: de que sonhos são sempre "satisfações de desejos". Freud (1996c[19161917]) nos contemplou, ainda, com outro insight a respeito da lucidez onírica: ele admitia que conteúdo visual, manifesto dos sonhos poderia ser modificado, porém a força-motriz intencional por trás dos sonhos continuava a ser inconsciente. Curiosamente, Freud nunca usou o termo "sonho lúcido" (LABERGE, 1990), apesar de se corresponder com o seu criador - o romancista e psiquiatria Frederik van Eeden (FREUD, 1996b).

O psicanalista Sándor Ferenczi (1873-1933) fez um breve artigo sobre o que denominou de "sonhos orientáveis" - inicialmente sonhos ruins modificados pelo sujeito para tornar o seu desfecho mais favorável. Tais "sonhos orientáveis" - uma mistura de pensamento consciente e inconsciente, diz Ferenczi (2011) - também são uma forma do sonhador prolongar a sua experiência onírica. Do ponto de vista desse psiquiatra húngaro, essas características dos "sonhos orientáveis" confirmam o postulado freudiano: os sonhos satisfazem desejos.

Pesquisadores de destaque na ciência dos sonhos lúcidos - Alan Moffitt, Paul Tholey, Jayne Gackenbach - criaram as suas próprias hipóteses a respeito da função psicológica da lucidez onírica. Pode-se dividir a contribuição desses autores em três categorias. Para eles o sonho lúcido, psicologicamente falando, serve como: (i) uma maneira do ego onírico de confrontar situações ou figuras ameaçadoras de forma criativa ou terapêutica, sem as resistências habituais; (ii) uma ferramenta cognitiva para o sonhador desenvolver a sua personalidade durante o sono, através da autorreflexão; (iii) uma forma de obter estados superiores de consciência, devido à semelhança fisiológica dos sonhos lúcidos com estados meditativos (GACKENBACH, 1991).

Carl Gustav Jung (1875-1961), criador da psicologia analítica, não mencionou a lucidez onírica em nenhum dos seus escritos, mas provavelmente estaria em desacordo com a visão freudiana dos sonhos lúcidos em alguns pontos - a começar pelo fato de duvidar que os sonhos sejam "senão a realização de um desejo" (JUNG, 1975, p. 279). Para Jung et al. (1977), o sonho na verdade opera por meio de um princípio "compensador", que equilibra o psiquismo do sujeito, corrigindo as deficiências da personalidade. Jung também divergia do seu colega Freud em outro aspecto: Freud acreditava que a "via régia" para o inconsciente eram os sonhos, enquanto Jung (2000a) acreditava que eram os complexos que desempenhavam esse papel. Eles são a chave para o inconsciente, onde se encontram as "raízes quase invisíveis do nosso pensamento" (JUNG et al., 1977, p. 43). A próxima seção tratará deles.

\section{À sombra dos complexos}

A psique humana é constituída por dois polos divergentes, o consciente e o inconsciente. À consciência pertence a moral convencional, o intelecto, o medir e quantificar, a motivação pra alcançar um ideal e o senso de planejamento para concretizá-lo. Apesar de voltada para a realidade, a consciência capta ela de maneira fragmentada, de trecho em trecho. A consciência tem um centro: o "eu" autorreflexivo (JUNG, 2000b, 2015).

Quanto ao inconsciente, Jung (2015) faz outra divisória: ele o separa em inconsciente pessoal e a sua camada mais profunda e arcaica, o inconsciente coletivo, base da psique. O primeiro é feito de conteúdos adquiridos na vida do indivíduo. Exemplos: coisas percebidas subliminarmente e desejos e pensamentos reprimidos pela consciência. Caso sejam trabalhados esses conteúdos podem ser reintegrados no consciente. O inconsciente coletivo, explica Jung (2000a), são disposições psíquicas herdadas da mente primitiva que podem ser explicadas à luz de lendas, mitos e contos de fada.

Referente ao inconsciente pessoal é oportuno mencionar o termo "complexo", utilizado pela primeira vez num contexto psicológico por Jung (1975). Essa foi a palavra designada pelo médico suíço para nomear os poderosos aglomerados de experiências afetivas que residem em nosso inconsciente, as psiques parciais que surgem personificadas em nossos sonhos (JUNG, 2000a). Essas "psiques cindidas" estão subtraídas ao comando hierarquizante da consciência do "eu" (JUNG, 1975).

Muitas vezes o complexo se origina através de um choque emocional, um trauma. Esse trauma promove uma "rachadura" na consciência e o fragmento desprendido desaparece no inconsciente. Essa dissociação é mantida por um conflito moral que empurra a fonte de atrito intrapsicológico para fora da visão normalmente estreita da consciência. Resultado: o complexo se porta quase como se fosse um corpo estranho para a consciência (JUNG, 2000a).

Às vezes os complexos irrompem na consciência, tomando, por assim dizer, as rédeas da psique quando a situação traumática reaparece e aí o complexo retorna com toda força. Jung (2000a) chamou esse processo de "constelação". Essas entidades psíquicas escapam, devido à sua marcada autonomia, "ao domínio da nossa vontade" (JUNG, 1975, p. 206).

Paramelhorcompreenderopapeldos complexosdentro da totalidade psíquica, é interessante tratar de um assunto caro para a psicologia analítica: o que Jung cunhou de "sombra". Para o médico suíço, a sombra designava tudo o que o paciente rejeitava em si, por não ser compatível com o estilo de vida escolhida pela sua consciência. A sombra tem um componente instintivo poderoso, então negá-la e reprimi-la pode ter consequências desastrosas (JUNG, 2015). A individualidade estará eternamente 
em construção, e escondida na sombra está o germe da nossa futura personalidade, o fermento para crescermos e mudarmos (JUNG, 1975).

\section{Reintegrando os fragmentos ou um diálogo com a sombra}

Na seção anterior, abordaram-se conceitos basilares da psicologia Junguiana: a teoria dos complexos e a sombra. Com o arcabouço teórico acumulado até o momento, como aplicá-lo ao tema do artigo? Pode-se iniciar com algo que Jung (1975) afirmou: que o "Outro" com quem sonhamos é o outro em nós, a quem não compreendemos ou aceitamos devido às tendências moralizadoras civilizatórias incutidas em nós na modernidade. Podemos ver essa perspectiva aproveitada nos sonhos lúcidos numa série de exemplos fornecidos por Garfield (1977) e LaBerge (1990), no qual eles usaram seu diálogo com o "Outro" para fins de desenvolvimento pessoal.

Garfield (1977, p. 39) descreve sua experiência:

[...] em um sonho, um estranho animal parecido com um cão arranha a minha mão. Esta imagem me intrigou, pois ocorreu durante uma época em que tal acontecimento em meus sonhos era raro. Ainda sonolenta, visualizei o animal do meu sonho. "Por que você me arranhou?", perguntei. "Eu não quis arranhá-la. Eu só queria que você prestasse mais atenção a mim", foi a resposta que ocorreu à minha mente. Esta resposta conduziu-me a novas reflexões sobre a imagem e eventualmente a um conhecimento maior de mim mesma.

LaBerge (1990) relatando o "sonho do ogro":

Sonhei que estava no meio de uma briga na sala de aulas; uma multidão furiosa vociferava, atirando cadeiras e trocando socos. Um bárbaro enorme e repugnante, de rosto marcado pela varíola, o Golias entre eles, estava me segurando com mão de ferro e não me deixava escapar, por mais desesperadamente que eu tentasse. Nesse ponto percebi que estava sonhando e, lembrando-me do que havia aprendido por ter lidado anteriormente com situações análogas, imediatamente parei de lutar. Logo que percebi a luta era um sonho, fiquei sabendo que o conflito, causado por uma questão de princípios, era comigo mesmo. Estava claro que aquele bárbaro repulsivo era a personificação de alguma coisa que eu queria negar e da qual queria me ver separado. Talvez fosse apenas a representação de alguém ou de alguma propriedade de outra pessoa, que eu não apreciava. Mas como, seja lá o que fosse, aquela coisa estava me sensibilizando íntima e profundamente o suficiente para que eu tivesse aquele sonho, fiquei sabendo que o caminho da harmonia interior estava em aceitar como parte de mim mesmo qualquer coisa que pudesse encontrar em mim (até aquele bárbaro odiento). Invariavelmente, agir dessa forma resolvia os meus conflitos do sonho e me levava para mais perto da minha meta de auto-integração (LABERGE, 1990, p. 22-23).

Apesar de não utilizarem nomenclaturas psicológicas específicas nesses relatos, Garfield e LaBerge claramente usaram sua lucidez onírica como uma oportunidade para reintegrarem fragmentos até então cindidos de suas psiques - simbolizados, respectivamente, pelo "estranho cão" e pelo "bárbaro repugnante". O próprio LaBerge
(1990, p. 19) menciona Jung e sua noção de "sombra" num trecho do livro Sonhos lúcidos e fala como sonhar lucidamente dá a capacidade "de enfrentar os próprios medos nos sonhos". Garfield (1977) também cita Jung no seu Sonhos Criativos. No entanto, a breve menção que faz ao psiquiatra suíço ressalta mais como Jung lidava com suas próprias fantasias do que alguma técnica da psicologia analítica.

A assim chamada " $7^{\circ}$ arte" pode oferecer subsídios adicionais à presente discussão - principalmente no que diz respeito aos filmes Waking Life e Vanilla Sky, ambos lançados em 2001. Aqui partimos do princípio exposto por Freud (1996d) no seu exame da Gradiva de Jensen, no qual defende que os sonhos criados por "escritores imaginativos" podem ser decifrados como se fossem sonhados mesmo de verdade, pois também revelariam materiais elaborados pelo inconsciente. Assume-se então que o mesmo princípio pode ser aplicado aos roteiros criados pelos diretores de Waking Life (Richard Linklater) e Vanilla Sky (Cameron Crowe).

Em Waking Life, o diretor texano Richard Linklater (Antes do Despertar, Fast Food Nation, O Homem Duplo, entre outros) explora o tema de sonhos lúcidos, usando como fio condutor da narrativa uma série de "falsos despertares" onde o protagonista, Wiley Wiggins, é guiado por uma awareness cada vez maior de sua passividade e alienação através do contato com seus diversos personagens oníricos. Wiggins é conduzido a uma jornada de autoconhecimento e conversa com diversos personagens oníricos - de professores de filosofia, biólogos até atores e atrizes de Hollywood (Ethan Hawke, July Delpy etc.) Um amplo espectro de temas são debatidos: o existencialismo segundo Sartre, a lógica da reencarnacionismo, a teoria da evolução hoje, entre outros.

Num determinado trecho, onde Wiggins começa a ter seus primeiros insights sobre a natureza do sonhar lúcido, ele comenta num de seus monólogos reflexivos que o seu sonho lúcido até agora é basicamente ele "lidando com várias pessoas que estão me expondo a informações e ideias que soam vagamente familiares [...] mas ao mesmo tempo, é tudo muito estranho para mim". Vê-se aí o binômio "estranheza / familiaridade" do "eu" diante dos outros complexos, situados abaixo do limiar da consciência. "Quase todas as pessoas que encontrei e as coisas que quero dizer [...] É como se elas as dissessem por mim, quase na minha deixa. É completo em si mesmo. Não é um sonho ruim", ressalta; só "[...] é tão diferente de qualquer outro sonho que eu já tive. É como se fosse 'o' sonho. Como se estivesse sendo preparado" (WAKING..., 2001).

Logo após, num outro diálogo interessante, um personagem que surge de um estacionamento (Steve Brudniak) diz: "Você ainda não conheceu a si mesmo. Mas a vantagem de conhecer outros, enquanto isso, é que um deles pode lhe apresentar a si mesmo". Brudniak então exorta Wiggins a examinar e a questionar a natureza do sonho. A nossa realidade é uma construção sensorial 
baseada num modelo mental. Num desenlace intrigante, vemos um representante da realidade interna incitando-o a questionar uma realidade externa.

Vanilla Sky, estrelado por Tom Cruise e Penélope Cruz, também trata de uma jornada de autoconhecimento através dos sonhos. O filme conta a história de David Aames (Cruise), um bon-vivant nova-iorquino herdeiro de um império de comunicação. Através de uma sequência de falsos despertares aterradores, ele descobre que está vivendo num sonho lúcido. A interação de Aames com sua galeria de personagens internos o faz "despertar" para a sua nova "realidade" - entre eles o terapeuta, Dr. Curtis McCabe (Kurt Russell), o melhor amigo, Brian Shelby (Jason Lee), e a mulher pela qual se apaixona, a bailarina Sofia Serrano (Cruz). A partir daí ele caminha não só para um despertar real, físico, mas também simbólico. ("Quero viver no mundo real. Não quero mais sonhar", diz Aames, na cena final.) Apesar do seu roteiro fictício, Vanilla Sky ilustra mais um caso onde personagens de sonhos lúcidos podem guiar o sujeito no seu "acordar" para uma realidade mais ampla. Como teria dito Jung (2000b), a "colaboração do inconsciente é sábia e orientada para a meta, e mesmo quando se comporta em oposição à consciência, sua expressão é sempre compensatória de um modo inteligente" (JUNG, 2000b, p. 275).

Outro ponto interessante a ser discutido é até que grau os personagens dos sonhos lúcidos podem ser considerados portadores de uma "consciência". Jung (2000b) diz que as expressões do inconsciente são geralmente caóticas e irracionais. E quanto às materializações antropomórficas presentes nos sonhos lúcidos? Jung (2000b) condiz que as manifestações do inconsciente tenham "certos sintomas" de inteligência e propósito e que podem parecer possuir a consciência de um "eu". No entanto, Jung (2000b) adverte que essas "entidades fantasmagóricas" são carentes de autorreflexão, algo próprio ao "eu" e da consciência. No ver do autor deste artigo eles apresentam um desafio à psicologia do sono Junguiana, pois apresentam a coerência e raciocínio igualáveis ao do eu, o centro da consciência.

A proposta de conferir tamanho grau de raciocínio aos complexos presentes nos sonhos lúcidos pode ser recebida com ceticismo; a própria existência de sonhos lúcidos foi questionada pelo analista americano James Albert Hall. Hall (2005, p. 111) inicialmente enxergou o sonhar lúcido como um "estado" o qual "ainda não vi convincentemente demonstrado" ainda. É importante dizer que James Hall fez tal asserção no seu livro Jung e a interpretação dos sonhos, publicado originalmente em 1983. Posteriormente, Hall e Brylowski (1991) escreveram um artigo comparando os sonhos lúcidos com uma das técnicas mais originais do repertório terapêutico Junguiano - a "imaginação ativa". Durante a imaginação ativa a consciência crítica é rebaixada e fantasias com energia psíquica de alta carga surgem sem a interferência do ego, e assim são criadas imagens mentais de forma autônoma e imprevisível. Apesar de ocorrem em estados fisiológicos diferentes - os sonhos lúcidos no sono REM versus e a imaginação ativa no estado de vigília - ambos são vistos por Hall e Brylowski (1991) como formas de fantasia privilegiadas em relação às interações entre o consciente e o inconsciente, contornando as resistências habituais do trabalho clínico.

Alguns insights interessantes a respeito da natureza desses "fantasmas" submersos na nossa inconsciência provêm de uma série de artigos do já mencionado Paul Tholey. Motivado pela curiosidade para descobrir as capacidades cognitivas dessas entidades oníricas, Tholey (1989) recrutou nove sonhadores lúcidos experientes do sexo masculino e pediu para eles, ao interagirem com seus complexos, fazerem as seguintes tarefas: 1) desenhar ou escrever; 2) uma palavra desconhecida; 3) compor um verso com rima; 4) e desempenhar um cálculo aritmético. Segundo Tholey (1989), a única onde área onde os personagens não obtiveram um desempenho satisfatório foi nas tarefas matemáticas. Segundo o ponto de vista fenomenológico adotado por Tholey (1989), nenhum desses resultados contradiz a noção de que os "personagens" que habitam os sonhos lúcidos não tenham consciência.

Sabe-se que, por terem notável autonomia e energia própria, os complexos, quando constelados, podem tomar o lugar do eu na consciência e a governarem (JUNG, 1975). Será que os complexos presentes durante um sonho lúcido não obedeceriam ao princípio? Seria tão absurdo supor que esses complexos tomam emprestada a energia da consciência de forma a se expressar na mesma linguagem do eu? A fisiologia oferece um indício dessas conjecturas: medições de eletroencefalograma (EEG) durante o sono REM revelam que durante um sonho lúcido há uma atividade acrescida no lóbulo parietal esquerdo, que é associada à capacidade semântica e à autoconsciência (HOLZINGER; LABERGE; LEVITAN, 2006).

A existência da lucidez onírica também desafia a acepção de Jung (1975, p. 112) de que "desempenhamos um papel essencialmente passivo" nos sonhos. Durante os sonhos lúcidos o sonhador fica mais participativo e menos no papel de um "simples observador" no desenrolar dos eventos oníricos (LABERGE, 1990). Cabe a uma nova geração de Junguianos decifrar as novas configurações psicológicas que podem ser extraídas dessa situação psicológica e analisar o possível simbolismo incutido nelas.

\section{Considerações finais: rumo à individuação}

A psique humana é constituída por dois polos divergentes; somados, eles formam o todo psicológico. A meta de uma psicoterapia é a harmonização entre essas duas metades discrepantes, chamada por Jung (2000b) de individuação. Essa união de opostos faz o sujeito tornarse cada vez mais singular, único (JUNG, 1991). Esse não é um processo fácil, pois não existe uma fórmula pronta para resolvê-lo. A individuação age de modo irracional, fora da alçada da consciência; então, o manuseio do simbólico é de suma importância (JUNG, 2000b).

Apesar do significado vital da individuação (pois a sua meta é a autorrealização plena do homem) os seus objetivos finais, alimentados pelas das tendências 
evolutivas do inconsciente, permanecerão sempre um mistério. Os insights obtidos dentro do setting terapêutico são uma contribuição valiosa nesse processo, pois deixam mais claro os caminhos tortuosos do desenvolvimento da personalidade. E os sonhos, disse Jung (1999), podem produzir esses insights, fornecendo pistas para o sujeito orientar de forma correta a sua trajetória rumo à totalidade psíquica.

Nesse sentido, Jung (1975, p. 98) afirma: "os sonhos são os melhores instrumentos para o estudo da própria essência do homem". Temos, então, de prestar atenção no que os personagens dos sonhos lúcidos têm a dizer. Temos de encará-los como mensageiros de nosso inconsciente, agentes de nossa individuação, pois o inconsciente e seus motivos "são muitas vezes" mais verdadeiros e lúcidos "do que o pensar consciente" (JUNG, 2000b, p. 275).

LaBerge (1990, p. 13) reforça os benefícios psicológicos do seu objeto de pesquisa:

[...] o sonho lúcido tem um potencial considerável na promoção do crescimento e do desenvolvimento pessoais, no aumento da confiança e na melhoria da saúde mental e física, além de facilitar a resolução de problemas de criatividade e ajudar a progredir no caminho do autocontrole.

Assim como o inconsciente em geral, a sombra se comporta de maneira compensatória em relação à consciência, e dessa matriz que o "eu" vai tirar suas novas possibilidades de subjetivação (JUNG, 1975, 2000b, 2015). Dos complexos e da sombra surgem uma nova luz, que nos conduz bravamente a possibilidades psíquicas dantes ignoradas, vindo a formar as bases para um futuro "eu".

\section{Referências}

BRYLOWSKI, A.; LEVITAN, L.; LABERGE, S. H-reflex suppression and autonomic activation during lucid REM sleep: a case study. Sleep, [S.1.], v. 12, n. 4, p. 374-378, 1989.

DEGRACIA, D. J. et al. Out-of-body experiences, dreams, and REM sleep. Sleep and Hypgnosis, [S.1.], v. 1, n. 3, p. 186-196, 1999.

ERLACHER, D.; SCHREDL, M. Cardiovascular responses to dreamed physical exercise during REM lucid dreaming. Dreaming, [S.1.], v. 18, n. 2, p. 112-121, 2008.

FERENCZI, S. Psicanálise I. São Paulo: WMF Martins Fontes, 2011.

FREUD, S. A interpretação dos sonhos (1900). In: STRACHEY, J. (Org.). Obras psicológicas completas de Sigmund Freud. Tradução de J. Salomão. Rio de Janeiro: Imago, 1996a. v. 4, p. 13-363. Edição Standard Brasileira.

FREUD, S. Carta a Frederik Van Eeden (1914). In: STRACHEY, J. (Org.). Obras psicológicas completas de Sigmund Freud. Tradução J. Salomão. Rio de Janeiro: Imago, 1996b. v. 14, p. 311-312. Edição Standard Brasileira.

FREUD, S. Conferências introdutórias sobre a psicanálise (1916-1917). In: STRACHEY, J. (Org.). Obras psicológicas completas de Sigmund Freud. Tradução de J. Salomão. Rio de Janeiro: Imago, 1996c. v. 15, p. 11-240. Edição Standard Brasileira.
FREUD, S. Delírios e sonhos na "Gradiva" de Jensen. In: STRACHEY, J. (Org.). Obras psicológicas completas de Sigmund Freud. Tradução de J. Salomão. Rio de Janeiro: Imago, 1996d. v. 9, p. 13-88. Edição Standard Brasileira.

GACKENBACH, J. Frameworks for understanding lucid dreaming: a review. Dreaming, \{S.1.], v. 1, n. 2, p. 109-128, 1991

GACKENBACK, J. Video game play and lucid dreams: implications for the development of consciousness. Dreaming, [S.1.], v. 16, n. 2, p. 96-110, 2006.

GARFIELD, P. Sonhos criativos. Rio de Janeiro: Nova Fronteira, 1977

GRAD, D. (1994). Aphex Twin vs. VapourSpace: fly in the machinery. Alternative Press, [S.1.], v. 9, n. 72, p. 42-45, 1994.

GREENLEAF, W.; KEDZIERSKI, B.; LABERGE, S. Physiological responses to dreamed sexual activity during lucid REM sleep. Psychophysiology, [S.1.], v. 20, n. 4, p. 454-455, 1983.

HALL, J. A. Jung e a interpretação dos sonhos: manual de teoria e prática. São Paulo: Cultrix, 2005.

HALL, J. A.; BRYLOWSKI, A. Lucid dreaming and active imagination: Implications for Junguian therapy. Quadrant, [S.1.], v. 24, n. 1, p. 34-43, 1991.

HOBSON, J. A. O cérebro sonhador. Lisboa: Instituto Piaget, 1996.

HOLZINGER, B.; LABERGE, S.; LEVITAN, L. Psychophysiological correlates of lucid dreaming. Dreaming, [S.1.], v. 16, n. 2, p. 88-95, 2006.

JUNG, C. G. O homem à descoberta da sua alma. Porto: Brasília, 1975.

JUNG, C. G. Estudos de psicologia analítica. Petrópolis: Vozes, 1991

JUNG, C. G. Ab-reação, análise dos sonhos, transferência. Petrópolis: Vozes, 1999.

JUNG, C. G. A natureza da psique. Petrópolis, RJ: Vozes, 2000a.

JUNG, C. G. Os arquétipos e o inconsciente coletivo. Petrópolis: Vozes, 2000b.

JUNG, C. G. Sonhos memórias reflexões. Rio de Janeiro: Nova Fronteira, 2015.

JUNG, C. G. et al. O homem e seus símbolos. Rio de Janeiro: Nova Fronteira, 1977.

KRIPPNER, S. Os primeiros curadores da humanidade: abordagens psicológicas e psiquiátricas sobre os xamãs e o xamanismo. Revista de Psiquiatria Clínica, [S.1.], v. 34, supl. 1, p. 17-24, 2007.

LABERGE, S. Lucid dreaming as a learnable skill: a case study. Perceptual and Motor Skills, [S.1.], v. 51, n. 3, p. 10391042, 1980.

LABERGE, S. Sonhos lúcidos. São Paulo: Siciliano, 1990.

LABERGE, S. Waking the dreamer. In: BROWN D. J.; NOVICK, R. M. (Org.). Mavericks of the mind: conversations for the new millennium. Freedom: The Crossing Press, 1993. p. 279-299. 
LEITE, T. M. Estado de consciência onírica. Psicologia USP [online], v. 8, n. 2, p. 287-304, 1997.

MARTIN, P. Counting sheep: the science and pleasures of sleep and dreams. New York: Thomas Dunne Books, 2004.

MUNIZ, C. M. A experiência onírica consciente: viagens da consciência ao mundo dos sonhos. Psicologia em Revista, [S.1.], v. 12, n. 1, p. 81-99, 2001.

MUNIZ, C. M. Reconhecendo a oniricidade: um estudo exploratório sobre a metacognição do estado onírico. Ciência \& Cognição, [S.1.], v. 5, p.67-83, 2005a.

MUNIZ, C. M. Sonhos lúcidos: o surgimento da lucidez onírica e o seu estudo. Ciência \& Cognição, [S.1.], v. 5, p. 50-66, 2005b.

PRENDERGAST, M. The ambient century: from Mahler to Moby - the evolution of sound in the electronic age. New York: Bloomsbury USA, 2003.

SAINT-DENYS, H. Les rêves et lês moyens de lês diriger (1867). Paris: Cartouche, 2007.

THOLEY, P. Relation between dream content and eye movements tested by lucid dreams. Perceptual and Motor Skills, [S.1.], v. 56, n. 3, p. 875-878, 1983 a.

THOLEY, P. Techniques for inducing and manipulating lucid dreams. Perceptual and Motor Skills, [S.1.], v. 57, n. 1, p. 7990, 1983b.

THOLEY, P. Consciousness and abilities of dream characters observed during lucid dreaming. Perceptual and Motor Skills, [S.1.], v. 68, n. 2, p. 567-578, 1989.

VANILLA Sky. Direção: Cameron Crowe. Produção: Tom Cruise; Paula Wagner e Cameron Crowe. Intérpretes: Tom Cruise; Penélope Cruz; Kurt Russel; Jason Lee; Noah Tyler; Cameron Diaz e outros. Roteiro: Cameron Crowe. Música: Nancy Wilson. [New York]: Paramount Pictures, 2001. 1 DVD (137 min), widescreen, color. Baseado no filme Abre los Ojos de Alejandro Amenábar e Mateo Gil.

WAKING life. Direção: Richard Linklater. Produção: Palmer West; Jonah Smith; Tommy Pallotta; e Anne Walker-McBay. Intérpretes: Wiley Wiggins e outros. Roteiro: Richard Linklater. Música: Tosca Tango Orchestra. [Austin]: Twentieth Century Fox, 2001. 1 DVD (101 min), widescreen, color.

Recebido em: 2 de julho de 2013

Aceito em: 1 de dezembro de 2015 